\title{
Recommendations for prioritization, treatment, and triage of breast cancer patients during the COVID-19 pandemic. the COVID-19 pandemic breast cancer consortium
}

\author{
Jill R. Dietz ${ }^{1,2,6} \cdot$ Meena S. Moran ${ }^{1,3,7} \cdot$ Steven J. Isakoff ${ }^{3,8} \cdot$ Scott H. Kurtzman ${ }^{1,9} \cdot$ Shawna C. Willey $^{2,10}$. \\ Harold J. Burstein ${ }^{3,11} \cdot$ Richard J. Bleicher ${ }^{1,12}$. Janice A. Lyons ${ }^{3,6}$. Terry Sarantou ${ }^{1,13} \cdot$ Paul L. Baron ${ }^{1,2,14}$. \\ Randy E. Stevens ${ }^{1,15}$. Susan K. Boolbol ${ }^{2,16}$. Benjamin O. Anderson ${ }^{3,17}$. Lawrence N. Shulman ${ }^{4,18}$. \\ William J. Gradishar ${ }^{3,19}$. Debra L. Monticciolo ${ }^{5,20}$. Donna M. Plecha ${ }^{5,6} \cdot$ Heidi Nelson ${ }^{1,4} \cdot$ Katharine A. Yao $^{1,21}$
}

Received: 8 April 2020 / Accepted: 10 April 2020 / Published online: 24 April 2020

(c) The Author(s) 2020

\begin{abstract}
The COVID-19 pandemic presents clinicians a unique set of challenges in managing breast cancer (BC) patients. As hospital resources and staff become more limited during the COVID-19 pandemic, it becomes critically important to define which $\mathrm{BC}$ patients require more urgent care and which patients can wait for treatment until the pandemic is over. In this Special Communication, we use expert opinion of representatives from multiple cancer care organizations to categorize $\mathrm{BC}$ patients into priority levels (A, B, C) for urgency of care across all specialties. Additionally, we provide treatment recommendations for each of these patient scenarios. Priority A patients have conditions that are immediately life threatening or symptomatic requiring urgent treatment. Priority B patients have conditions that do not require immediate treatment but should start treatment before the pandemic is over. Priority $\mathrm{C}$ patients have conditions that can be safely deferred until the pandemic is over. The implementation of these recommendations for patient triage, which are based on the highest level available evidence, must be adapted to current availability of hospital resources and severity of the COVID-19 pandemic in each region of the country. Additionally, the risk of disease progression and worse outcomes for patients need to be weighed against the risk of patient and staff exposure to SARS CoV-2 (virus associated with the COVID-19 pandemic). Physicians should use these recommendations to prioritize care for their $\mathrm{BC}$ patients and adapt treatment recommendations to the local context at their hospital.
\end{abstract}

Jill R. Dietz

Jill.Dietz@UHhospitals.org

1 National Accreditation Program for Breast Centers, Chicago, IL, USA

2 American Society of Breast Surgeons, Columbia, MD, USA

3 National Comprehensive Cancer Network, Plymouth Meeting, PA, USA

4 Commission On Cancer, Chicago, IL, USA

5 American College of Radiology, Reston, VA, USA

6 University Hospital Cleveland Medical Center, Cleveland, OH, USA

7 Yale Medicine, New Haven, CT, USA

8 Massachusetts General Hospital Cancer Center, Boston, MA, USA

9 Waterbury Hospital, Waterbury, CT, USA
10 Inova Schar Cancer Institute, Fairfax, VA, USA

11 Dana Farber Cancer Institute, Boston, MA, USA

12 Fox Chase Cancer Center, Philadelphia, PA, USA

13 Carolinas Medical Center, Charlotte, NC, USA

14 Montefiore Medical Center, Bronx, NY, USA

15 White Plains Hospital, White Plains, NY, USA

16 Nuvance Hospital, Poughkeepsie, NY, USA

17 University of Washington, Seattle, WA, USA

18 University of Pennsylvania, Philadelphia, PA, USA

19 Northwestern Medicine, Chicago, IL, USA

20 Baylor Scott \& White Healthcare-Central Texas, Temple, TX, USA

21 NorthShore University HealthSystem, Evanston, IL, USA 


\section{Introduction}

The COVID-19 pandemic poses unprecedented challenges for patients, clinicians, and healthcare systems. Across every facet of medicine, clinicians are responding to the pandemic by modifying patient care to minimize exposure risk and preserve resources, and the management of patients with cancer poses unique challenges [1]. To provide preliminary guidance on the prioritization and treatment of breast cancer (BC) during this severe acute respiratory syndrome coronavirus 2 (SARS-CoV-2) outbreak, we assembled representatives from the American Society of Breast Surgeons (ASBrS), the National Accreditation Program for Breast Centers (NAPBC), the National Comprehensive Care Network (NCCN), the Commission on Cancer (CoC) and the American College of Radiology (ACR) to formulate an Expert Opinion. The objective of this Special Communication is to prioritize patient scenarios by urgency of treatment by specialty and to make treatment recommendations based on these priorities within each specialty. Given the rapidly evolving nature of the COVID-19 pandemic, time constraints prohibited a formal consensus statement.

These recommendations relate specifically to $\mathrm{BC}$ patients not suspected to have COVID-19-related illness. We acknowledge that there are limited prospective experiences to guide these recommendations. Furthermore, these recommendations are driven by the common goal to preserve hospital resources for virus-inflicted patients by deferring BC treatments without significantly compromising long-term outcomes for individual $\mathrm{BC}$ patients. The demands that the COVID-19 pandemic will place on healthcare institutions remain unpredictable and will have geographical variability. Therefore, the risks of disease progression and compromised BC-specific outcomes need to be weighed against viral exposure to patients and staff, taking into consideration each individual's comorbidities and age to predict risk of mortality from COVID-19. Lastly, these are recommendations and are not intended to supersede individual physician judgment or institutional policies and guidelines.

\section{Methods}

After extensive multidisciplinary teleconference discussions and literature review, a "Priority" classification for BC patients was developed across the disciplines. Priority categories were defined based on the severity of an individual patient's condition (including patient comorbidities) and potential efficacy of treatments [2].

\section{Priority A category}

Priority A patients have a condition that is immediately life threatening, clinically unstable, or completely intolerable and for whom even a short delay would significantly alter the patient's prognosis. Assuming efficacious treatment, these patients are given top priority even if resources become scarce, requiring urgent treatment for preservation of life or control of progressing disease or symptomatic relief.

\section{Priority B category}

Patients in the Priority B category are patients who do not have immediately life-threatening conditions but for whom treatment or services should not be indefinitely delayed until the end of the pandemic. Most BC patients will fall under Priority B. If conditions in a geographic location only allow for Priority A patients to receive treatment, then treatment for Priority B patients can be delayed for a defined period of time during the pandemic. A short delay (e.g. 6-12 weeks) would not impact overall outcome for these patients. Longer delays could impact outcomes in some Priority B patients and triage may become necessary to justify which patients should undergo treatment versus further delay. Patients within the Priority B category will be sub-stratified as B1 (higher priority), B2 (mid-level priority), and B3 (lower priority) as defined by each BC subspecialty.

\section{Priority C category:}

Patients in Priority C category are patients for whom certain treatment or services can be indefinitely deferred until the pandemic is over without adversely impacting outcomes.

\section{Results}

Priority categories and treatment recommendations by specialty are listed below.

\section{Outpatient visits}

During the pandemic, the majority of encounters should be conducted remotely via telemedicine. Decisions to conduct in-person visits must carefully weigh the risk of viral transmission to patients and healthcare providers with the need for an in-person evaluation. Priority A includes, for example, clinically unstable postoperative patients and those with potential medical oncologic emergencies (e.g. febrile neutropenia, intractable pain) who need to be assessed inperson. Priority B patients should be evaluated by at least 
one member of the multidisciplinary team in-person or remotely depending on need. These include newly diagnosed BC patients; established patients with new problems (breast infection, palpable findings, and significant symptoms from therapy); patients on active IV chemotherapy; patients completing neoadjuvant therapy preparing for surgery; routine postoperative patients; and patients being evaluated and planned for radiation therapy. Priority $\mathrm{C}$ patients are those presenting for routine follow-up for benign or malignant conditions (including those on oral adjuvant agents and those not on active treatment), survivorship visits, or highrisk screening and can be seen remotely or delayed until the postpandemic period. Increased precautions should be taken surrounding in-person visits/treatments for patients with comorbidities and a high risk of COVID-19 complications.

\section{Breast focused imaging}

Few scenarios are designated Priority A for breast imaging, with the exception of imaging for urgent situations such as a severe breast abscess formation or for evaluation of a serious postoperative complication..

Table 1 Priority categories for surgical oncology

\begin{tabular}{|c|c|c|}
\hline Priority & Patient description & COVID-19 treatment considerations \\
\hline \multicolumn{3}{|c|}{ Priority A } \\
\hline A & Breast abscess in a septic patient & Operative drainage if unable to be drained at the bedside \\
\hline A & Expanding hematoma in a hemodynamically unstable patient & Operative evacuation and control of bleeding \\
\hline \multicolumn{3}{|c|}{ Priority B } \\
\hline B1 & Ischemic autologous tissue flap & Revascularize or remove flap \\
\hline B1 & $\begin{array}{l}\text { Revision of a full thickness ischemic mastectomy flap with } \\
\text { exposed prosthesis }\end{array}$ & Debride and remove expander/implant \\
\hline B1 & $\begin{array}{l}\text { Patients who have completed neoadjuvant chemotherapy for } \\
\text { Inflammatory BC }\end{array}$ & Operate as soon as possible depending on institutional resources* \\
\hline B1 & TNBC and HER $2+$ patients & $\begin{array}{l}\text { Neoadjuvant chemotherapy or HER } 2 \text { targeted therapy. In some } \\
\text { cases, institutions may decide to proceed with surgery first } \\
\text { versus neoadjuvant therapy. These decisions will depend on } \\
\text { institutional resources and patient factors.* }\end{array}$ \\
\hline B2 & $\begin{array}{l}\text { Neoadjuvant: } \\
\text {-finishing treatment } \\
\text {-progressing on treatment }\end{array}$ & $\begin{array}{l}\text { Operate if feasible depending on resources or extend/change } \\
\text { neoadjuvant therapy* }\end{array}$ \\
\hline B3 & Clinical Stage T2 or N1 ER +/ HER2 - tumors & Consider hormonal treatment, delay operation \\
\hline B3 & Discordant biopsies likely to be malignant & Perform excisional biopsy when conditions allow \\
\hline B3 & Malignant or suspected local recurrence & $\begin{array}{l}\text { Begin with staging when feasible. Perform excision when condi- } \\
\text { tions allow if there is no distant disease }\end{array}$ \\
\hline \multicolumn{3}{|c|}{ Priority $\mathrm{C}$} \\
\hline $\mathrm{C} 1$ & ER-DCIS & $\begin{array}{l}\text { Delay operation until after COVID-19 unless there is a high risk } \\
\text { of invasive cancer (Move to B3) }\end{array}$ \\
\hline $\mathrm{C} 1$ & Positive margin(s) for invasive cancer & Delay re-excision until after COVID-19 \\
\hline $\mathrm{C} 1$ & Clinical Stage T1N0 ER +/ HER2—cancers & Hormonal treatment; delay operation until after COVID-19 \\
\hline $\mathrm{C} 1$ & $\mathrm{BC}$ patients requiring additional axillary surgery & Delay operation until after COVID-19 \\
\hline $\mathrm{C} 2$ & $\mathrm{ER}+\mathrm{DCIS}$ & Hormonal treatment; delay operation until after COVID-19 \\
\hline $\mathrm{C} 2$ & High-risk lesions & Delay operation until after COVID-19 \\
\hline $\mathrm{C} 2$ & Reconstruction for previously completed mastectomy & Delay operation until after COVID-19 \\
\hline $\mathrm{C} 3$ & $\begin{array}{l}\text { Excision of benign lesions-fibroadenomas, nodules, papillomas, } \\
\text { etc }\end{array}$ & Delay operation until after COVID-19 \\
\hline $\mathrm{C} 3$ & Discordant biopsies likely to be benign & Delay operation until after COVID-19 \\
\hline $\mathrm{C} 3$ & Prophylactic surgery-for cancer and noncancer & Delay operation until after COVID-19 \\
\hline
\end{tabular}

*Breast conservation is preferred provided that radiation oncology services are available, and the risk of multiple visits or deferred radiation is acceptable. If no ventilator is available or risk of viral exposure is high, breast conserving surgery could be performed under local with sedation. Reconstruction should be limited to tissue expander or implant placement if necessary depending on institutional resources. Autologous reconstruction should be deferred

$B C$ breast cancer, $T N B C$ triple negative breast cancer, ER estrogen receptor, HER2 human epidermal growth factor receptor 2, DCIS ductal carcinoma in situ 
Breast imaging Priority B includes diagnostic imaging for an abnormal mammogram or for suspicious breast symptoms, biopsies for BI-RADS 4 or 5 lesions, and breast MRI for extent of disease evaluation or pre-chemotherapy assessment. Biopsies for lower suspicion lesions (BI-RADS 4a) may be postponed or biopsied. BI-RADS category 3 patients returning for short-term follow-up diagnostic mammogram and/or ultrasound and routine breast examination should be postponed until the COVID-19 pandemic is over and would be Priority C. All screening examinations including mammography, ultrasound, and MRI should be placed in Priority $\mathrm{C}$ and suspended until the post-COVID-19 period. BRCA mutation carriers under the age of 40 may be considered for screening if delays of more than 6 months are expected $[3,4]$.

\section{Surgical oncology}

Table 1 lists patient scenarios into Priority categories for urgency of surgical care. The need to minimize use of operating room resources requires selectively deferring surgery and triaging patients for use of an initial alternative therapy whenever possible. However, level II evidence demonstrates that preoperative delays may impact $\mathrm{BC}$ outcomes $[5,6]$.

Invasive $\mathrm{BC}$ patients should be triaged with multidisciplinary input and assessment of patient's risks and comorbidities to potentially receive neoadjuvant therapies during the pandemic. While neoadjuvant chemotherapy confers risks of immunosuppression and uses personal protective equipment (PPE), high-risk breast cancers would fall in Priority $B$ because upfront surgery is not required when systemic treatment is initiated. Current standards for triple negative breast cancer (TNBC) and human epidermal growth factor 2-overexpressing (HER2+) BC already include neoadjuvant therapy, which has very high rates of clinical and pathological tumor response affording durable tumor control prior to deferred surgery $[7,8]$

Patients completing neoadjuvant chemotherapy are categorized as Priority B1. Delays of surgery up to 8 weeks postchemotherapy do not adversely affect BC outcomes [9]. Breast imaging cannot be used as a surrogate to assess pathologic response because false negative rates vary between 17.8 and 50\% [10-13] In the event that resources do not allow for surgery, additional non-surgical therapy should be considered (see Medical Oncology section).

Patients with hormone receptor-positive $\mathrm{BC}$ are Priority $\mathrm{B} 3$ or $\mathrm{C}$ because neoadjuvant endocrine therapy allows for deferment of definitive surgery. Studies evaluating tamoxifen with/without surgery demonstrate no difference in survival within the first three years suggesting that short-term deferment of surgery with endocrine therapy should not adversely impact BC-specific survival [14-16]
Patients eligible for breast conservation should be discouraged from elective mastectomy depending on local institutional resources. For patients requiring mastectomy, immediate reconstruction with implant or tissue expanders can be performed only if hospital resources permit. Autologous reconstruction should be deferred [17]

Discordant biopsies are uncommon, but when they occur, establishing the presence of malignancy is required [18]. These patients would be categorized in Priority B or C depending on level of suspicion.

For newly diagnosed, recurrent BC, staging evaluation is preferred but may be unavailable. Surgery is typically indicated only in the absence of metastatic disease. Treatment will depend on resource availability (see Medical Oncology section).

Re-operation for margins or axillary staging is Priority $\mathrm{C}$ when there is a low likelihood of residual disease [19]. Patients with estrogen receptor-positive (ER + ) ductal carcinoma in situ (DCIS) and low volume ER- DCIS are Priority $\mathrm{C} 1$ whereas patients at high-risk for occult invasion are Priority B3. Non-operative trials, however, are limited to low-risk DCIS [20-22].

Practitioners caring for $\mathrm{BC}$ see many benign conditions. If a malignant lesion is unlikely, diagnostic procedures should be postponed. It is advisable to follow-up with patients whose treatment is being altered or postponed. The enormity of changes from the COVID-19 pandemic itself is anxiety-provoking among patients and practitioners. Patient psychological well-being needs to be considered and often can be addressed with telemedicine/phone visits. While shared decision-making is ideal, in the context of the pandemic difficult choices must be made.

\section{Medical oncology}

Table 2 lists patient scenarios into Priority categories for urgency of either hormonal, chemotherapy and/or targeted therapy. The medical oncology goals are to minimize patient interactions with healthcare centers, maintain patient safety, and conserve resources while providing effective care. All specialty and institutional goals and patient factors should be considered when formulating a treatment plan. Priority A patients are those with oncologic emergencies requiring immediate treatment (e.g. febrile neutropenia, intractable pain). Priority B patients require systemic care but are candidates for modified therapeutic approaches to achieve the goals above; the urgency and therapeutic options are stratified into higher-to-lower priorities (B1-B3). Priority $\mathrm{C}$ patients can delay interventions for many months without adverse impact on survival or quality of life. 
Table 2 Priority categories for medical oncology

\begin{tabular}{|c|c|c|}
\hline Priority & Patient description & COVID-19 treatment considerations \\
\hline \multicolumn{3}{|c|}{ Priority A } \\
\hline A & $\begin{array}{l}\text { Patients with oncologic emergencies (e.g. febrile neutropenia, } \\
\text { hypercalcemia, intolerable pain, symptomatic pleural effusions } \\
\text { or brain metastases, etc.) }\end{array}$ & Initiate necessary management \\
\hline \multicolumn{3}{|c|}{ Priority B } \\
\hline B1 & Patients with inflammatory $\mathrm{BC}$ & Neoadjuvant chemotherapy \\
\hline $\mathrm{B} 1$ & Patients with TNBC or HER $2+\mathrm{BC}$ & Neo/adjuvant chemotherapy (Neoadjuvant for $\geq \mathrm{T} 2$ or N1) \\
\hline $\mathrm{B} 1$ & $\begin{array}{l}\text { Patients with mBC for whom therapy is likely to improve out- } \\
\text { comes }\end{array}$ & Initiate chemotherapy, endocrine, or targeted therapy \\
\hline $\mathrm{B} 1$ & Patients who already started neo/adjuvant chemotherapy & $\begin{array}{l}\text { Continue therapy until complete (if neoadjuvant and responding, } \\
\text { can extend treatment if necessary to defer surgery further) }\end{array}$ \\
\hline $\mathrm{B} 1$ & Patients progressing on neoadjuvant therapy & Refer to surgery or change systemic therapy \\
\hline B1 & Patients on oral adjuvant endocrine therapy & Continue therapy \\
\hline B1 & $\begin{array}{l}\text { Premenopausal patients with } \mathrm{ER}+\mathrm{BC} \text { receiving LHRH agonists } \\
\text { (adjuvant or metastatic) }\end{array}$ & $\begin{array}{l}\text { - If on aromatase inhibitor, continue LHRH agonist and con- } \\
\text { sider long acting } 3 \text { month dosing or home administration } \\
\text { - If on tamoxifen, consider deferring LHRH agonist }\end{array}$ \\
\hline $\mathrm{B} 1$ & Patients with clinical anatomic Stage 1 or $2 \mathrm{ER}+/ \mathrm{HER} 2-\mathrm{BCs}$ & $\begin{array}{l}\text { Neoadjuvant endocrine therapy for } 6 \text { to } 12 \text { months to defer sur- } \\
\text { gery (may consider gene expression assay on core biopsy) }\end{array}$ \\
\hline B2 & Patients receiving treatment for Stage $1 \mathrm{HER} 2+$ breast & $\begin{array}{l}\text { Ado-trastuzumab emtansine may be substituted for paclitaxel/ } \\
\text { trastuzumab }\end{array}$ \\
\hline B3 & Patients with ER + DCIS & Consider neoadjuvant endocrine therapy to defer surgery \\
\hline B3 & $\begin{array}{l}\text { Patients with } \mathrm{mBC} \text { for whom therapy is unlikely to improve } \\
\text { outcomes }\end{array}$ & Consider deferring chemotherapy, endocrine, or targeted therapy \\
\hline B3 & $\begin{array}{l}\text { Patients with HER } 2+\mathrm{mBC} \text { beyond } 2 \text { years of maintenance } \\
\text { antibody therapy (trastuzumab, pertuzumab) with minimal } \\
\text { disease burden }\end{array}$ & $\begin{array}{l}\text { Consider stopping antibody therapy with monitoring for progres- } \\
\text { sion every } 3-6 \text { months }\end{array}$ \\
\hline B3 & Patients with HER $2+\mathrm{BC}$ receiving adjuvant antibody treatment & $\begin{array}{l}\text { Consider curtailing antibody treatment after } 7 \text { months instead of } \\
12 \text { months }\end{array}$ \\
\hline \multicolumn{3}{|c|}{ Priority C } \\
\hline $\mathrm{C}$ & Patients receiving zoledronic acid, denosumab & Discontinue bone antiresorptive therapy unless for hypercalcemia \\
\hline $\mathrm{C}$ & Patients with stable $\mathrm{mBC}$ & Interval for routine follow-up restaging studies can be delayed \\
\hline $\mathrm{C}$ & $\begin{array}{l}\text { Patients with lower risk imaging findings needing follow-up } \\
\text { (e.g., small pulmonary nodules) }\end{array}$ & Interval follow-up can be delayed \\
\hline $\mathrm{C}$ & $\begin{array}{l}\text { Patients who are candidates for prevention measures (e.g. family } \\
\text { history, LCIS or ADH, BRCA1/2+) }\end{array}$ & $\begin{array}{l}\text { Consider endocrine therapy (as appropriate), delay surgery and } \\
\text { screening imaging }\end{array}$ \\
\hline $\mathrm{C}$ & Patients in long-term follow-up for early BC & Defer routine in-person visit \\
\hline $\mathrm{C}$ & Patients on aromatase inhibitors & Defer bone density testing (baseline and follow-up) \\
\hline
\end{tabular}

$B C$ breast cancer, $T N B C$ triple negative breast cancer, $m B C$ metastatic $\mathrm{BC}, L H R H$ luteinizing hormone releasing hormone, $E R$ estrogen receptor, $H E R 2$ human epidermal growth factor receptor 2, DCIS ductal carcinoma in situ, LCIS lobular carcinoma in situ, ADH atypical ductal hyperplasia

\section{Invasive BC-early stage}

For newly diagnosed BC patients, multidisciplinary plans can be revised to protect patients and spare healthcare services (Priority B). Depending on local circumstances, surgery, systemic therapy, and radiation therapy (RT) sequencing may be altered to ensure patient safety and healthcare system needs. Neoadjuvant treatment is well established for all BC subtypes and enables delayed surgery. If necessary, RT can be given before adjuvant chemotherapy (especially for ER + tumors) without affecting long-term outcomes [23].
Patients with ER +, HER2- tumors can defer surgery and receive neoadjuvant endocrine therapy for 6 to 12 months without clinical compromise (Priority B1) [24, 25]. Patients should be assessed periodically to confirm the absence of tumor progression. Patients with Stage 1 or limited Stage 2 disease (including those with N1 nodal involvement), and those with low-intermediate grade tumors, lobular BCs, low-risk genomic assays (especially the recurrence score, which may be sent from a core biopsy [26]), or "luminal A" signatures, do not benefit substantially from neoadjuvant or 
adjuvant chemotherapy [27, 28]. These patients may receive endocrine therapy alone.

TNBC patients should receive standard chemotherapy approaches (Priority B1), and all BC subtypes currently receiving neoadjuvant or adjuvant treatment should complete standard regimens already underway. Abbreviated schedules or dose modified regimens may be considered. Single-agent sequential therapy may reduce treatment complications without compromising efficacy [29].

Patients with Stage 1 or 2, HER2 + BCs may consider ado-trastuzumab emtansine ( \pm pertuzumab) with comparable efficacy to chemotherapy/trastuzumab-based regimens in either neoadjuvant or adjuvant settings (Priority B2) to minimize neutropenia, visits, and steroid-use [30, 31]. Adjuvant trastuzumab-based therapy may be shortened from 12 to 6 months without affecting outcomes in selected patients (Priority B3) [32, 33].

\section{Invasive BC—advanced stage}

Patients with advanced (metastatic) BC have many treatment options and typically receive multiple lines of therapy which are rarely dependent on specific treatment sequencing. Dose and schedule adjustments of systemic treatments are reasonable to reduce clinic visits, bloodwork, and development of significant side effects. Patients without signs or symptoms of tumor progression may defer routine restaging scans. When the likely benefit of additional palliative chemotherapy is very small, patients may find the risks of treatment outweigh the possible gains in outcome.

Trastuzumab, pertuzumab, and related antibody-drug conjugates for HER2 + tumors may be given at less frequent dosing intervals, as necessary. Patients with HER2 + BC with $>2$ years duration of tumor control and minimal disease burden with trastuzumab-based regimens may consider interrupting maintenance therapy [34].

The use of oral targeted agents (CDK4/6, mTOR, and PIK3CA inhibitors) in $\mathrm{ER}+$, metastatic $\mathrm{BC}$ must be weighed against the increased risk of adverse events. Dose reductions can minimize treatment-related toxicities. CDK4/6 inhibitors as first-/second-line treatment offer clinical advantage, but may be delayed if the likelihood of tumor control is high with endocrine therapy alone (first line, no prior endocrine treatment, no visceral disease) [35]. Dose reduction of palbociclib does not diminish efficacy $[36,37]$.

\section{High-risk lesions and pre-invasive BC}

High-risk lesions such as atypical hyperplasia and lobular carcinoma in situ express ER and are effectively treated with either tamoxifen or aromatase inhibitors [38, 39]. ER + DCIS can be treated with preoperative endocrine therapy for 6 months (Priority C) [40]. For management of ER- disease see Surgical Oncology section.

Table 3 Additional considerations for priority categories for medical oncology

\begin{tabular}{|c|c|}
\hline Agent & Dosing and scheduling considerations \\
\hline Chemotherapy & $\begin{array}{l}\text { Chemotherapy schedules may be modified to reduce clinic visits (using } 2 \text { - or } 3 \text {-week dosing, e.g.) or to reduce infection risk } \\
\text { (using weekly dosing) for selected agents when appropriate } \\
\text { For low-risk febrile neutropenia, outpatient regimens may be used } \\
\text { Selected patients (particularly with ER + disease), can consider radiation before chemotherapy if this facilitates patient safety }\end{array}$ \\
\hline Targeted therapy & $\begin{array}{l}\text { The addition of oral targeted agents (CDK 4/6, mTOR, or PIK3CA inhibitors) to endocrine therapy may be delayed in first- } \\
\text { line treatment, or in situations where endocrine therapy alone is providing or is likely to provide effective tumor control } \\
\text { Cardiac monitoring (Echo, nuclear) during HER } 2 \text { antibody therapy can be delayed or discontinued if clinically stable } \\
\text { Consider reduced dose of oral targeted agents to optimize tolerability and minimize treatment-related toxicities } \\
\text { Trastuzumab and pertuzumab for metastatic HER2 + BC may reasonably be administered at longer intervals (e.g. } 4 \text { weeks) }\end{array}$ \\
\hline Endocrine therapy & $\begin{array}{l}\text { Oral endocrine agents (e.g. tamoxifen, aromatase inhibitors) are not immunosuppressive and can be safely continued } \\
\text { Fulvestrant is not immunosuppressive but requires monthly clinical administration } \\
\text { Aromatase inhibitors are preferred over tamoxifen for neoadjuvant endocrine therapy (and LHRH agonists should be used } \\
\text { for premenopausal women) }\end{array}$ \\
\hline Supportive care & $\begin{array}{l}\text { Extend venous access device (port) flush to } 12 \text { weeks or longer } \\
\text { Consider peripheral venous access for IV chemotherapy if patient has sufficient veins and no existing port if institutional } \\
\text { policies permit } \\
\text { Administer G-CSF growth factor support to minimize neutropenia } \\
\text { Limit dexamethasone when possible to reduce immunosuppression }\end{array}$ \\
\hline
\end{tabular}

$E R$ estrogen receptor, $L H R H$ luteinizing hormone releasing hormone, HER2 human epidermal growth factor receptor 2, IV intravenous, $G$ - $C S F$ granulocyte colony-stimulating factor 


\section{Supportive care and additional considerations}

Endocrine treatments (tamoxifen, aromatase inhibitors, luteinizing hormone releasing hormone (LHRH) agonist) are safe and can be continued thru the COVID-19 pandemic (Table 3). LHRH agonists may be given every 3 months, and home administration is an option [41]. Patients receiving chemotherapy should receive appropriate supportive care to reduce side effects; in particular, granulocyte colony-stimulating factor (G-CSF) should be used to minimize neutropenia, and can be considered for regimens with $<20 \%$ chance of febrile neutropenia not usually offered G-CSF. Interventions that alleviate severe symptoms should remain a high priority. Bone modifying treatments (intravenous bisphosphonates or denosumab) can be deferred in patients without hypercalcemia, on adjuvant therapy, or on long-standing courses of therapy.

\section{Radiation oncology}

Radiation therapy (RT) plays an integral role in the treatment of many BCs. Patient-related factors (age, comorbidities) contributing to infection risk must be carefully weighed against the risk of worsened $\mathrm{BC}$ outcomes if delaying the anticipated local-regional and potential survival benefits of RT. Priority A includes patients presenting with symptomatic disease in whom short palliative RT regimens should be utilized [42-44]. Patients clinically progressing on neoadjuvant therapy should be considered for a longer definitive preoperative hypofractionated (HF) regimen to reduce risk of continued progression if surgically unresectable or resource constraints prohibit timely surgery $[45,46]$.

The majority of RT referrals will likely be Priority $\mathrm{B}$ requiring triage/deferment. Limited published data on RT delays in the definitive setting are inconsistent. Locally advanced or inflammatory patients may have worse outcomes after neoadjuvant chemotherapy if RT is delayed $>8$ weeks (Priority B1) [47]. In contrast, delaying RT 20 weeks in early-stage, ER + patients after BCS demonstrates no difference in outcomes compared to 4-8 weeks (Priority B3) [48]. Since Priority B sub-stratifies by clinicalpathologic recurrence risk, $\mathrm{B} 1$ patients should be given priority over B2 or B3; hypofractionated (HF) regimens should be strongly considered whenever possible. Long-term outcomes with HF-RT utilizing $42.5 \mathrm{~Gy} / 16$ or $40 \mathrm{~Gy} / 15$ fractions demonstrate safety and efficacy similar to conventional fractionation which will reduce patient/staff exposure [45,
46]. Though regional-nodal and postmastectomy patients were under-represented in these trials, historic [49] and emerging [50] data suggest no differences in efficacy or toxicity for these sub-groups. Current trials are evaluating HF with reconstruction (Alliance221505/ NCT03414970; FABREC Trial/ NCT03422003). Furthermore, additional intensive regimens after lumpectomy (FAST: 28.5 Gy in 5 once-weekly fractions [51, 52]; FAST Forward: 26 Gy in 5 fractions over 1 week [53]) suggest early toxicity comparable to $40 \mathrm{~Gy} / 15$ fractions. These regimens may be considered in selected patients undergoing breast RT (without regional-nodal RT). Similarly, a boost should be reserved for patients with greatest absolute benefit (e.g., positive margins, age $\leq 40)$ [54].

Priority C patients are those in whom RT does not affect survival outcomes and includes all DCIS with exception of ER- DCIS with positive margins (Priority B3), if re-excision is not possible. Patients $\geq 65-70$ years with early-stage, node negative, ER + invasive disease should start endocrine therapy after surgery, with RT safely omitted or deferred until the pandemic is over $[55,56]$. A mechanism should be in place to re-evaluate patients for whom standard RT therapy is deferred so that recurrences/disease progression can be detected and managed appropriately (Table 4).

\section{Discussion}

The three priority levels we have defined reflect the urgency of treatment during this pandemic resulting in multidisciplinary management recommendations taking into account the burden of the COVID-19 pandemic on our health system.

\section{Hospital factors to consider in prioritization of BC patients}

It is critical for physicians to understand the rapidly changing local conditions and available resources as well as risks/ benefits of various treatments for patients, staff, and hospital systems. Evolving local conditions and resources will influence which priority category receives treatment. Factors to consider include supply and equipment inventory (ventilators, PPE) and availability of intensive care and inpatient beds. Other factors would be the proportion of healthcare personnel infected with SARS CoV-2, and whether BC treatment will put healthcare workers at risk. Finally, the prevalence of regional community transmission will determine hospital capacity for outpatient care. These aforementioned factors will determine which $\mathrm{BC}$ patients receive treatment during or after the pandemic resolves. 
Table 4 Priority categories for radiation oncology

\begin{tabular}{|c|c|c|}
\hline Priority & Patient Description & COVID-19 Treatment Considerations \\
\hline \multicolumn{3}{|c|}{ Priority A } \\
\hline A & $\begin{array}{l}\text { Bleeding/painful inoperable local-regional disease, } \\
\text { Symptomatic metastatic disease }\end{array}$ & Consider palliative HF regimens \\
\hline A & Progression of disease during NAC & Consider definitive HF regimens \\
\hline \multicolumn{3}{|c|}{ Priority B } \\
\hline B1 & Inflammatory BC s/p mastectomy & Consider PMRT HF regimens \\
\hline B1 & $\begin{array}{l}\text { Node positive: TNBC or HER } 2+\text { disease s/p BCT or } \\
\text { mastectomy }\end{array}$ & Consider WBRT or PMRT HF regimens \\
\hline B1 & Postmastectomy with 4 or more tumor-positive nodes & Consider PMRT HF regimens \\
\hline B1 & Residual node-positive disease after NAC & Consider WBRT or PMRT regimens \\
\hline B2 & PMRT with 1-3 tumor-positive nodes & Consider PMRT HF regimens \\
\hline B2 & Node negative: TNBC or HER $2+\mathrm{s} / \mathrm{p} \mathrm{BCT}$ & Consider WBRT HF regimens \\
\hline $\mathrm{B} 2$ & $\begin{array}{l}\text { If tumor-positive margin after BCT for invasive BC } \\
\text { with no alternative therapy options* }\end{array}$ & Consider WBRT HF regimens \\
\hline B3 & $\begin{array}{l}\text { If tumor-positive margin after BCT for invasive BC } \\
\text { with alternative therapy options }\end{array}$ & Consider WBRT HF regimens \\
\hline B3 & $\begin{array}{l}\text { Young age }(\leq 40 \text { years }) \text { s/p BCT, node negative } \\
\text { with } \geq 1 \text { additional high-risk features (LVI }+ \\
\text { PNI }+)\end{array}$ & Consider HF regimens \\
\hline B3 & ER-DCIS with a positive margin & Consider HF WBRT regimens \\
\hline \multicolumn{3}{|c|}{ Priority C } \\
\hline $\mathrm{C}$ & DCIS $^{* * *}$ & $\begin{array}{l}\text { Initiate endocrine therapy if ER + Defer radiation } \\
\text { therapy until pandemic is over }\end{array}$ \\
\hline $\mathrm{C}$ & $\begin{array}{l}>65 \text { years early-stage, nodenegative ER + / HER2- } \\
\text { taking adjuvant endocrine therapy s/p BCT }\end{array}$ & $\begin{array}{l}\text { Omit radiation therapy or defer until pandemic is } \\
\text { over }\end{array}$ \\
\hline \multicolumn{3}{|c|}{ Hypofractionated Regimens: } \\
\hline \multicolumn{3}{|c|}{ Palliative Radiation } \\
\hline $4 \mathrm{~Gy}$ & & Meta-analysis [43] \\
\hline $8 \mathrm{~Gy}$ & & RTOG 97-14 [42] \\
\hline \multicolumn{3}{|c|}{ Whole breast radiation therapy: } \\
\hline 2.67 & & START B [45] \\
\hline 2.66 & & Canadian [46] \\
\hline $5.7 \mathrm{G}$ & & FAST [52] \\
\hline $5.2-5$ & & FAST Forward [53] \\
\hline \multicolumn{3}{|c|}{ Postmastectomy radiation therapy: } \\
\hline \multicolumn{2}{|c|}{$\begin{array}{l}2.5 \text { Gy daily } \times 15 \text { to chest wall total } 37.50 \mathrm{~Gy} ; 2.5 \text { Gy daily } \times 14 \text { to regional nodes (including IMN) total } \\
35 \text { Gy }\end{array}$} & British Columbia PMRT trial [49] \\
\hline \multicolumn{2}{|c|}{$2.90 \mathrm{~Gy} \times 15$ daily to chest wall, SC \& Level III axilla total 43.5 Gy } & China PMRT Trial [50] \\
\hline \multicolumn{2}{|r|}{ IMN) total $42.56 \mathrm{~Gy}$} & NCT03414970 \\
\hline \multicolumn{2}{|c|}{2.67 Gy daily $\times 15$ to chest wall total $40.05 \mathrm{~Gy}, 2.67 \times 14$ to RNI total $37.38 \mathrm{~Gy}$} & NCT03422003 \\
\hline \multicolumn{3}{|l|}{ Boost } \\
\hline \multicolumn{3}{|c|}{$2.5 \mathrm{~Gy} \times 4$ total $10 \mathrm{~Gy}$, consider additional $2.5 \mathrm{~Gy}$ fraction for positive margin } \\
\hline \multicolumn{3}{|c|}{ Considerations for treatment interruptions } \\
\hline \multicolumn{3}{|c|}{$\begin{array}{l}\text { No change to WBRT, PMRT dose. Adjust boost as follows: } \\
\text { No boost in original treatment plan: Add boost } 2.5 \mathrm{~Gy} \times 4 \\
\text { Boost in original treatment plan: consider additional } 2.5 \mathrm{~Gy} f \mathrm{fr}\end{array}$} \\
\hline
\end{tabular}

$B C$ breast cancer, $T N B C$ triple negative breast cancer, $H F$ hypofractionated, $N A C$ neoadjuvant chemotherapy, $P M R T$ postmastectomy radiation therapy, WBRT whole breast radiation therapy, $B C T$ breast conserving therapy, LVI lymphovascular invasion, $P N I$ peri-neural invasion, ER estrogen receptor, HER2 human epidermal growth factor receptor 2, IMN internal mammary node; $R N I$ regional-nodal irradiation

*TNBC with tumor positive margins should be given priority over TNBC with negative margins

**Exception to DCIS in Priority C is ER-negative DCIS with positive margin

***Adapted from Gay HA, et al. [57] 


\section{Importance of the multidisciplinary approach to the $B C$ patient}

The basic tenets of cancer care coordination should be followed as much as possible during the COVID-19 pandemic. Management of BC patients requires a highly integrated and multidisciplinary approach. An intervention in one specialty will have a direct impact on another specialty. For example, the American College of Surgeons issued a statement that elective surgeries should be canceled [17]. Fortunately, many BC patients do not need upfront surgical resection because of neoadjuvant treatment options. However, deferring $\mathrm{BC}$ cases will initially increase the medical oncologist workload and will result in a backlog of procedures when the pandemic resolves. For these reasons, multidisciplinary discussion documenting Priority category for surgery and/or adjuvant treatments is necessary to ensure the best outcomes for patients. If feasible, tumor board discussions should include both standard and COVID-19 recommendations based on institution's level of pandemic severity. Documentation of these discussions in the medical record is highly recommended.

\section{Future directions}

This information should be used to organize a process of structured decision-making for the care of patients with breast disease during the COVID-19 pandemic. However, as the pandemic rapidly evolves, we are increasingly learning about viral transmission and its impact on the health system; thus, these recommendations will evolve over time with continued updates. This consortium will continue to adapt these recommendations to the current pandemic severity including future waves of the COVID-19 pandemic. It is our hope that these current recommendations will help clinicians provide the highest quality care for their patients during this evolving pandemic.

Funding There was no funding source.

Open Access This article is licensed under a Creative Commons Attribution 4.0 International License, which permits use, sharing, adaptation, distribution and reproduction in any medium or format, as long as you give appropriate credit to the original author(s) and the source, provide a link to the Creative Commons licence, and indicate if changes were made. The images or other third party material in this article are included in the article's Creative Commons licence, unless indicated otherwise in a credit line to the material. If material is not included in the article's Creative Commons licence and your intended use is not permitted by statutory regulation or exceeds the permitted use, you will need to obtain permission directly from the copyright holder. To view a copy of this licence, visit http://creativecommons.org/licenses/by/4.0/.

\section{References}

1. Ueda M, Martins R, Hendrie PC et al (2020) Managing Cancer Care During the COVID-19 Pandemic Agility and Collaboration Toward a Common Goal. J Nat Comprehen Cancer Net 1:1-4

2. Ontario Health. Pandemic Planning Clinical Guideline for Patients with Cancer. 2020. https://www.accc-cancer.org/docs/ documents/cancer-program-fundamentals/oh-cco-pandemicplanning-clinical-guideline_final_2020-03-10.pdf. Accessed 23 March 2020.

3. Armes JE, Egan AJ, Southey MC et al (1998) The histologic phenotypes of breast carcinoma occurring before age 40 years in women with and without BRCA1 or BRCA2 germline mutations: a population-based study. Cancer 83(11):2335-2345

4. Monticciolo DL, Newell MS, Moy L, Niell B, Monsees B, Sickles EA (2018) Breast Cancer Screening in Women at Higher-ThanAverage Risk: Recommendations From the ACR. J Am College Radiol 15(3):408-414

5. Bleicher RJ, Ruth K, Sigurdson ER et al (2016) Time to Surgery and Breast Cancer Survival in the United States. JAMA Oncol 2(3):330-339

6. Ward WH, DeMora L, Handorf E et al (2020) Preoperative Delays in the Treatment of DCIS and the Associated Incidence of Invasive Breast Cancer. Ann Surg Oncol 27(2):386-396

7. Sikov WM, Berry DA, Perou CM et al (2015) Impact of the addition of carboplatin and/or bevacizumab to neoadjuvant once-perweek paclitaxel followed by dose-dense doxorubicin and cyclophosphamide on pathologic complete response rates in stage II to III triple-negative breast cancer: CALGB 40603 (Alliance). J Clin Oncol 33(1):13-21

8. von Minckwitz G, Huang CS, Mano MS et al (2019) Trastuzumab Emtansine for Residual Invasive HER2-Positive Breast Cancer. N Engl J Med 380(7):617-628

9. Sanford RA, Lei X, Barcenas $\mathrm{CH}$ et al (2016) Impact of Time from Completion of Neoadjuvant Chemotherapy to Surgery on Survival Outcomes in Breast Cancer Patients. Ann Surg Oncol 23(5):1515-1521

10. Basik M, Cecchini RS, Santos JFDL et al (2020) Cancer Res 80(4):GS5

11. Heil J, Pfob A, Sinn H-PP et al (2020) Abstract GS5-03: Diagnosing residual disease and pathologic complete response after neoadjuvant chemotherapy in breast cancer patients by imageguided vacuum-assisted breast biopsy: Results of a prospective multicenter trial. Can Res 80(4):5-03

12. Peeters M-JTFDV, van Loevezijn A, van der Noordaa ME et al (2020) Abstract GS5-06: Towards omitting breast surgery in patients with a pathologic complete response after neoadjuvant systemic treatment: interim analysis of the MICRA trial (Minimally Invasive Complete Response Assessment). Can Res 80(4):5-06

13. Tasoulis MK, Lee H-B, Yang W et al (2020) Abstract GS5-04 Accuracy of post-neoadjuvant chemotherapy image-guided breast biopsy to predict the presence of residual cancer: a multi-institutional pooled analysis. Can Res 80(4):5-04

14. Fennessy M, Bates T, MacRae K, Riley D, Houghton J, Baum M (2004) Late follow-up of a randomized trial of surgery plus tamoxifen versus tamoxifen alone in women aged over 70 years with operable breast cancer. Br J Surg 91(6):699-704

15. Mustacchi G, Ceccherini R, Milani S et al (2003) Tamoxifen alone versus adjuvant tamoxifen for operable breast cancer of the elderly: long-term results of the phase III randomized controlled multicenter GRETA trial. Ann Oncol 14(3):414-420

16. Mustacchi G, Milani S, Pluchinotta A, De Matteis A, Rubagotti A, Perrota A (1994) Tamoxifen or surgery plus tamoxifen as primary treatment for elderly patients with operable breast cancer: The 
G.R.E.T.A. Trial. Group for Research on Endocrine Therapy in the Elderly. Anticancer Res. 14(5B):2197-2200

17. American College of Surgeons. COVID-19 Guidelines for Triage of Breast Cancer Patients. https://www.facs.org/covid-19/clinicalguidance/elective-case/breast-cancer. Published 2020. Accessed March 29, 2020.

18. Bluemke DA, Gatsonis CA, Chen MH et al (2004) Magnetic resonance imaging of the breast prior to biopsy. JAMA 292(22):2735-2742

19. Findlay-Shirras LJ, Outbih O, Muzyka CN, Galloway K, Hebbard PC, Nashed M (2018) Predictors of Residual Disease After Breast Conservation Surgery. Ann Surg Oncol 25(7):1936-1942

20. Elshof LE, Tryfonidis K, Slaets L et al (2015) Feasibility of a prospective, randomised, open-label, international multicentre, phase III, non-inferiority trial to assess the safety of active surveillance for low risk ductal carcinoma in situ - The LORD study. Eur J Cancer 51(12):1497-1510

21. Francis A, Thomas J, Fallowfield L et al (2015) Addressing overtreatment of screen detected DCIS; the LORIS trial. Eur J Cancer 51(16):2296-2303

22. Youngwirth LM, Boughey JC, Hwang ES (2017) Surgery versus monitoring and endocrine therapy for low-risk DCIS: The COMET Trial. Bull Am Coll Surg 102(1):62-63

23. Bellon JR, Come SE, Gelman RS et al (2005) Sequencing of chemotherapy and radiation therapy in early-stage breast cancer: updated results of a prospective randomized trial. J Clin Oncol 23(9):1934-1940

24. Masuda N, Sagara Y, Kinoshita T et al (2012) Neoadjuvant anastrozole versus tamoxifen in patients receiving goserelin for premenopausal breast cancer (STAGE): a double-blind, randomised phase 3 trial. Lancet Oncol 13(4):345-352

25. Spring LM, Gupta A, Reynolds KL et al (2016) Neoadjuvant Endocrine Therapy for Estrogen Receptor-Positive Breast Cancer: A Systematic Review and Meta-analysis. JAMA Oncol 2(11):1477-1486

26. Iwata H, Masuda N, Yamamoto $Y$ et al (2019) Validation of the 21-gene test as a predictor of clinical response to neoadjuvant hormonal therapy for ER+, HER2-negative breast cancer: the TransNEOS study. Breast Cancer Res Treat 173(1):123-133

27. Nitz U, Gluz O, Christgen M et al (2017) Reducing chemotherapy use in clinically high-risk, genomically low-risk pN0 and pN1 early breast cancer patients: five-year data from the prospective, randomised phase 3 West German Study Group (WSG) PlanB trial. Breast Cancer Res Treat 165(3):573-583

28. Sparano JA, Gray RJ, Makower DF et al (2018) Adjuvant Chemotherapy Guided by a 21-Gene Expression Assay in Breast Cancer. N Engl J Med 379(2):111-121

29. Citron ML, Berry DA, Cirrincione C et al (2003) Randomized trial of dose-dense versus conventionally scheduled and sequential versus concurrent combination chemotherapy as postoperative adjuvant treatment of node-positive primary breast cancer: first report of Intergroup Trial C9741/Cancer and Leukemia Group B Trial 9741. J Clin Oncol 21(8):1431-1439

30. Hurvitz SA, Martin M, Jung KH et al (2019) Neoadjuvant Trastuzumab Emtansine and Pertuzumab in Human Epidermal Growth Factor Receptor 2-Positive Breast Cancer: Three-Year Outcomes From the Phase III KRISTINE Study. J Clin Oncol 37(25):2206-2216

31. Tolaney SM, Trippa L, Barry W et al (2020) Abstract GS1-05: TBCRC 033 A randomized phase II study of adjuvant trastuzumab emtansine (T-DM1) vs paclitaxel (T) in combination with trastuzumab $(\mathrm{H})$ for stage I HER2-positive breast cancer (BC) (ATEMPT). Can Res 80(4):1-05

32. Earl HM, Hiller L, Vallier AL et al (2019) 6 versus 12 months of adjuvant trastuzumab for HER2-positive early breast cancer (PERSEPHONE): 4-year disease-free survival results of a randomised phase 3 non-inferiority trial. Lancet 393(10191):2599-2612

33. Pivot X, Romieu G, Debled M et al (2019) 6 months versus 12 months of adjuvant trastuzumab in early breast cancer (PHARE): final analysis of a multicentre, open-label, phase 3 randomised trial. Lancet 393(10191):2591-2598

34. Moilanen T, Mustanoja S, Karihtala P, Koivunen JP (2017) Retrospective analysis of HER2 therapy interruption in patients responding to the treatment in metastatic HER2+ breast cancer. ESMO Open 2(3):e000202

35. Spring LM, Wander SA, Andre F, Moy B, Turner NC, Bardia A (2020) Cyclin-dependent kinase 4 and 6 inhibitors for hormone receptor-positive breast cancer: past, present, and future. Lancet 395(10226):817-827

36. Parulekar W, Joy A, Gelmon K et al (2019) Abstract PD1-10 Randomized phase II study comparing two different schedules of palbociclib plus second line endocrine therapy in women with estrogen receptor positive, HER2 negative advanced/metastatic breast cancer: CCTG MA38 (NCT02630693). Can Res 79(4):1-10

37. Zheng J, Yu Y, Durairaj C et al (2018) Abstract P5-21-21 Palbociclib exposure-response analyses in the treatment of hormonereceptor positive $(\mathrm{HR}+)$, human epidermal growth factor receptor 2 negative (HER2-) advanced breast cancer (ABC). Can Res 78(4):5-21

38. Cuzick J, Sestak I, Forbes JF et al (2014) Anastrozole for prevention of breast cancer in high-risk postmenopausal women (IBISII): an international, double-blind, randomised placebo-controlled trial. Lancet 383(9922): 1041-1048

39. Fisher B, Costantino JP, Wickerham DL et al (1998) Tamoxifen for prevention of breast cancer: report of the National Surgical Adjuvant Breast and Bowel Project P-1 Study. J Natl Cancer Inst 90(18):1371-1388

40. Hwang ES, Hyslop T, Hendrix LH, et al. (2020) Phase II SingleArm Study of Preoperative Letrozole for Estrogen Receptor-Positive Postmenopausal Ductal Carcinoma In Situ CALGB 40903 (Alliance). J Clin Oncol. 19.

41. Masuda N, Iwata H, Rai Y et al (2011) Monthly versus 3-monthly goserelin acetate treatment in pre-menopausal patients with estrogen receptor-positive early breast cancer. Breast Cancer Res Treat 126(2):443-451

42. Hartsell WF, Scott CB, Bruner DW et al (2005) Randomized trial of short- versus long-course radiotherapy for palliation of painful bone metastases. J Natl Cancer Inst 97(11):798-804

43. Chow E, Harris K, Fan G, Tsao M, Sze WM (2007) Palliative Radiotherapy Trials for Bone Metastases: a Systematic Review. J Clin Oncol 25(11):1423-1436

44. Choi HS, Jang HS, Kang KM, Choi B-o (2019) Symptom palliation of hypofractionated radiotherapy for patients with incurable inflammatory breast cancer. Radiation Oncology 14(1):110

45. Haviland JS, Owen JR, Dewar JA et al (2013) The UK Standardisation of Breast Radiotherapy (START) trials of radiotherapy hypofractionation for treatment of early breast cancer: 10-year follow-up results of two randomised controlled trials. Lancet Oncol 14(11):1086-1094

46. Whelan TJ, Pignol JP, Levine MN et al (2010) Long-term results of hypofractionated radiation therapy for breast cancer. N Engl J Med 362(6):513-520

47. Silva SB, Pereira AAL, Marta GN et al (2018) Clinical impact of adjuvant radiation therapy delay after neoadjuvant chemotherapy in locally advanced breast cancer. Breast 38:39-44

48. Olivotto IA, Lesperance ML, Truong PT et al (2009) Intervals longer than 20 weeks from breast-conserving surgery to radiation therapy are associated with inferior outcome for women with early-stage breast cancer who are not receiving chemotherapy. J Clin Oncol 27(1):16-23 
49. Ragaz J, Jackson SM, Le N et al (1997) Adjuvant radiotherapy and chemotherapy in node-positive premenopausal women with breast cancer. N Engl J Med 337(14):956-962

50. Wang SL, Fang H, Song YW et al (2019) Hypofractionated versus conventional fractionated postmastectomy radiotherapy for patients with high-risk breast cancer: a randomised, non-inferiority, open-label, phase 3 trial. Lancet Oncol 20(3):352-360

51. group FT, Agrawal RK, Alhasso A et al (2011) First results of the randomised UK FAST Trial of radiotherapy hypofractionation for treatment of early breast cancer (CRUKE/04/015). Radiother Oncol 100(1):93-100

52. Brunt AM. FAST Trial 10 year results ASTRO 2018 Annual Meeting presentation slides ASTRO 2018.

53. Brunt AM, Wheatley D, Yarnold J et al (2016) Acute skin toxicity associated with a 1-week schedule of whole breast radiotherapy compared with a standard 3-week regimen delivered in the UK FAST-Forward Trial. Radiother Oncol 120(1):114-118

54. Jones HA, Antonini N, Hart AA et al (2009) Impact of pathological characteristics on local relapse after breast-conserving therapy: a subgroup analysis of the EORTC boost versus no boost trial. J Clini Oncol 27(30):4939-4947
55. Hughes KS, Schnaper LA, Bellon JR et al (2013) Lumpectomy Plus Tamoxifen With or Without Irradiation in Women Age 70 Years or Older With Early Breast Cancer: Long-Term Follow-Up of CALGB 9343. J Clin Oncol 31(19):2382-2387

56. Kunkler IH, Williams LJ, Jack WJL, Cameron DA, Dixon JM (2015) Breast-conserving surgery with or without irradiation in women aged 65 years or older with early breast cancer (PRIME II): a randomised controlled trial. Lancet Oncol 16(3):266-273

57. Gay HA, Santiago R, Gil B et al (2019) Lessons Learned From Hurricane Maria in Puerto Rico: Practical Measures to Mitigate the Impact of a Catastrophic Natural Disaster on Radiation Oncology Patients. Pract Radiat Oncol 9(5):305-321

Publisher's Note Springer Nature remains neutral with regard to jurisdictional claims in published maps and institutional affiliations. 